\title{
Buerger's Disease
}

\author{
Yusuke Fukuda, Yuta Kato, Shin-ichiro Miura and Keijiro Saku
}

Key words: Buerger's disease, smoking, claudication, Raynaud's phenomenon

(Intern Med 52: 639, 2013)

(DOI: 10.2169/internalmedicine.52.9394)

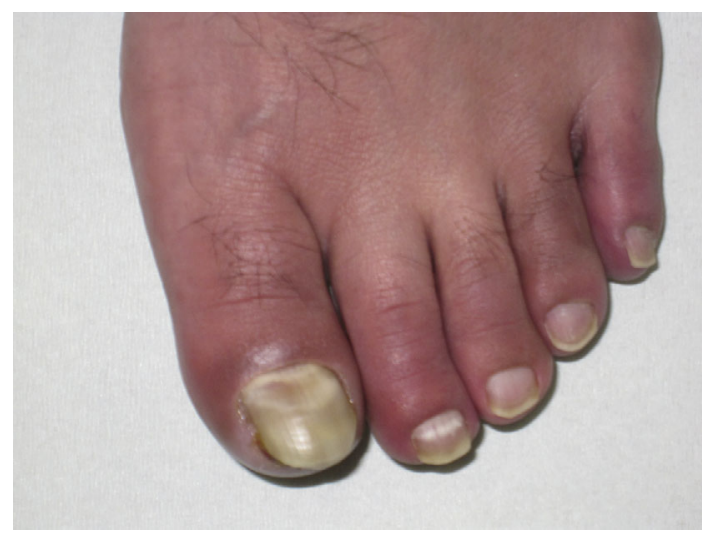

Picture 1.

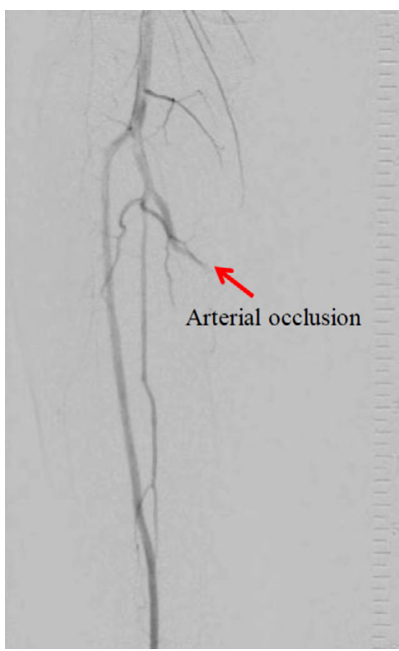

Picture 3.

A 42-year-old man was admitted to our hospital with a painful and pale toe (Picture 1). He had experienced Raynaud's phenomenon and extremity claudication which had started some years ago.

An abnormal Allen test and thermography (Picture 2)

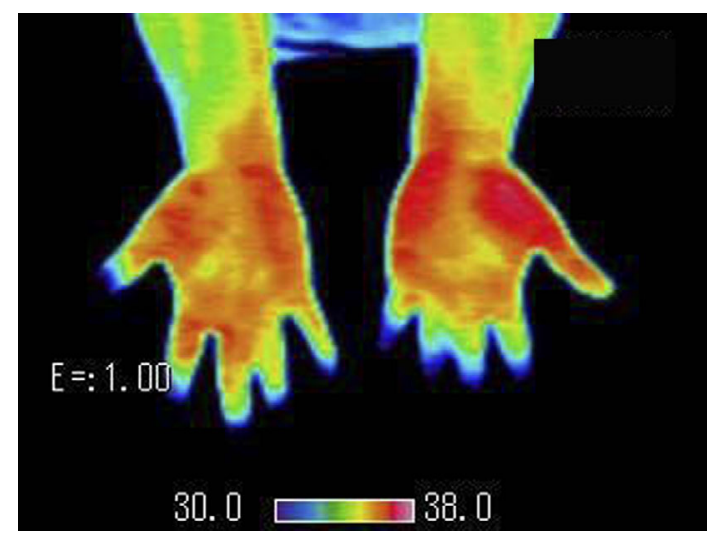

Picture 2.

demonstrated upper extremity ischemia. Angiography of the lower extremities demonstrated arterial occlusion without atherosclerosis in arteries below the knee (Picture 3).

The patient was healthy and without any atherosclerotic risk factors other than smoking. These phenomena were diagnosed as Buerger's disease based on Shionoya's clinical criteria, as follows: 1) a history of smoking, 2) onset before 50 years of age, 3 ) the presence of infrapopliteal arterial occlusions, 4) either upper limb involvement or phlebitis migrans and 5) the absence of atherosclerotic risk factors other than smoking (1).

There is a close relationship between tobacco smoking and Buerger's disease. Cessation of tobacco smoking and the administration of prostacyclin and a calcium channel blocker improved the patient's leg pain and skin color.

The authors state that they have no Conflict of Interest (COI).

\section{Reference}

1. Shionoya S. Diagnostic criteria of Buerger's disease. Int J Cardiol 66 Suppl 1: S243-S245; discussion S247, 1998.

Department of Cardiology, Fukuoka University School of Medicine, Japan

Received for publication November 23, 2012; Accepted for publication November 27, 2012

Correspondence to Dr. Yusuke Fukuda, zfukusuke@minf.med.fukuoka-u.ac.jp

(C) 2013 The Japanese Society of Internal Medicine Journal Website: http://www.naika.or.jp/imonline/index.html 